\title{
El imaginario de Estados Unidos en dos libros de viajes de Julián Marías yJosep Pla de los años cincuenta
}

\author{
MARIA DASCA BATALLA
}

HarvardUniversity

\begin{abstract}
Resumen
En este artículo se analizan los libros de viajes Los Estados Unidos en escorzo (1956), de Julián Marías y Viaje a América (1960), de Josep Pla, teniendo en cuenta la tradición de literatura de viajes sobre Estados Unidos publicada en Europa a partir de 1945 y en España a partir de 1953, año de la firma de los acuerdos bilaterales entre el gobierno norteamericano y el franquista. Más concretamente, nos centraremos en el análisis contextual, formal e imagológico de estas dos obras, a través de las cuales los autores difunden unas formas de vida y de cultura norteamericanas relacionadas con la introducción gradual de la filosofía mercantil del libre comercio en España.
\end{abstract}

\begin{abstract}
In this paper I analyse two travel books: Los Estados Unidos en escorzo (1956), written by Julián Marías, and Viaje a América (1960), by Josep Pla. We take into account the tradition of travel literature to the United States published (in Europe) after 1945 and (in Spain) after 1953, the year of the bilateral agreement between the Francoist regime and the government of the United States. More specifically, the study focuses on the contextual, formal and imagological analysis of both works, through which Marías and Pla disseminate their knowledge of some aspects of the North American way of life and culture related to the gradual introduction in Spain of the commercial philosophy of free trade.
\end{abstract}

Qu'est-ce qu'une idée ? C'est une image qui se peint dans mon cerveau. Voltaire, 'Idée', Dictionnairephilosophique(1764)

Los libros Los Estados Unidos en escorzo (1956), de Julián Marías, y Viaje a América (1960), de Josep Pla, publicados anteriormente en forma de artículos en el $A B C$ y Destino, respectivamente, son el resultado de un determinado contexto histórico, literario y cultural. En un primer lugar, los relacionaremos con los libros de viajes sobre los Estados Unidos publicados en Europa justo después de la primera guerra 
mundial. Como veremos, estas obras conectan con una tradición de literatura periodística y ensayística iniciada, en España, a finales del siglo XIX y dirigida a la incipiente sociedad de masas (Alarcón Sierra 2015: 11). En segundo lugar, nos centraremos en los elementos constitutivos del subgénero literatura de viajes extrapolables a los dos libros, considerando la atracción que supone el género, debidamente difundido a través de la prensa, en cuanto a la creación de lectores. Finalmente, analizaremos el imaginario norteamericano construido por Marías y Pla desde la perspectiva de los estudios imagológicos y, más concretamente, la terminología adoptada por el comparatista Daniel-Henri Pageaux (1994) y los especialistas en imagología Joep Leerssen y Manfred Beller (2007). En este último punto, observaremos cómo la voluntad divulgativa de ambos escritores no está exenta de un determinado posicionamiento subjetivo que contribuye a la elaboración de nuevos estereotipos de clase y de género.

A nuestro entender, el análisis contextual, formal y imagológico de estas dos obras nos permite observar críticamente cómo se elaboran unos determinados valores sociales y culturales atribuidos al carácter presuntamente norteamericano, que son dependientes, sin duda, del marco de expectativas en que se articula el relato del escritor-viajero, claramente determinado por factores de orden ideológico. Este fenómeno nos interesa en la medida que, al desarrollarse en unos años decisivos para la difusión internacional de la cultura norteamericana, constituye un rico ejemplo del marco de significaciones que tiene (y adquiere) esta cultura en el contexto europeo de postguerra. Adoptando esta perspectiva nos planteamos, por tanto, desarrollar un estudio de historia de las mentalidades y las sensibilidades culturales. Más concretamente, el análisis de este caso concreto nos ayudará a entender cómo los escritores reflejan la manera de funcionar de una sociedad (la que produce una determinada imagen de una cultura externa) en base a su ideología, sistema literario e imaginario social (Pageaux 1994: 60).

\section{El contexto histórico}

Es a partir de finales del siglo XIX que se publica, de forma continuada, una literatura de viajes a los Estados Unidos (Miranda-Barreiro 2014). Periodistas, diplomáticos y científicos, que viajan por motivos profesionales, exponen su visión del país a partir de temas como las minorías étnico-culturales, los medios de comunicación, la publicidad, la industria, los transportes, la religión, el espacio público, las ciudades, la educación, el paisaje, la mujer y el ocio (García-Montón 2002). A inicios del XX crece el mito de Nueva York, ciudad que ganará importancia con el desarrollo de la industria cinematográfica y que será el centro de las prosas poéticas y las poesías del Diario de un poeta reciéncasado (1916) de Juan Ramón Jiménez y de las crónicas que Julio Camba recoge en Un año en el otro mundo (1917) (Alarcón Sierra 2015: 11; 2010: 140-42; Camba 1959).

Esta tradición de literatura de viajes forma parte, de hecho, de una corriente europea difundida por los libros de Paul Morand, André Maurois y Le Corbusier, entre otros. Más concretamente, Morand le dedicó el libro de 1930 New York, una 
obra planteada como 'construction symphonique' (Pinçonnat 2001: 41) donde la ciudad se caracteriza por la fuerza de sus contrastes (Morand 1930: 262-76). Maurois, por su lado, se convirtió en uno de los grandes divulgadores de la cultura estadounidense con sus libros En Amérique (1933), États-Unis 39: journal d'un voyage en Amérique (1939) y Journal États-Unis, 1946 (1946), además de su Histoire des ÉtatsUnis (1944), publicada en dos volúmenes (Maurois 1945). Su relato, focalizado en la experiencia social, cultural y, sobre todo, académica, se desarrolla paralelamente a la de Maurice Coindreau, prolífico traductor de novela norteamericana al francés. Le Corbusier, finalmente, se siente atraído por el frenetismo de la multitud y la belleza, a la vez sublime y atroz, de los rascacielos -estos son los temas nucleares de su libro Quand les cathédrales étaient blanches. Voyage au pays des timides (1937) (Le Corbusier 1965).

En la España de los años treinta destacan, por la modernidad de su visión, los textos de Federico García Lorca (Poeta en Nueva York, con poemas escritos entre 1929 y 1930; véase García Lorca 1987), Julio Camba (con su crónica del viaje recogida en La ciudad automática, 1932; véase Camba 2015) y Enrique Jardiel Poncela (que difundirá sus viajes, de 1932-1933 y 1934-1935, en el semanario Nuevo Mundo, entre otros (véase Jardiel Poncela 1955)). Son tres casos suficientemente conocidos que contribuyen a la difusión de la imagen de Nueva York como ciudad-mundo, fragmentaria y patética (Lorca), ciudad automática regida por la mecánica fordista (Camba) (Alarcón Sierra 2005; y 2010: 139-53) y ciudad con calles sin término, por donde se esparcen imágenes fugaces de su gente y sus edificios (Jardiel Poncela 1955: 41-50).

Todo este interés se mantiene y se transforma a partir de los años cuarenta; especialmente después de la segunda guerra mundial, cuya resolución supone unos cambios geoestratégicos que afianzan la emergencia de Estados Unidos como nuevo centro mundial, mientras que Nueva York mantiene su hegemonía como capital-mundo. En un primer lugar, son los escritores existencialistas, Sartre, Camus y Beauvoir, quienes inician una gira por los Estados Unidos. Sartre es invitado por el Departamento de Estado norteamericano, mientras que los viajes de Camus y Beauvoir están motivados por intereses literarios y culturales (Huvos 1972). Es interesante constatar que los tres difundieron su testimonio mediante la prensa (Sartre publicó sus crónicas en Combat y Le Figaro) o dietarios: los Journaux de voyage de Camus (aparecidos póstumamente, el 1975; véase Camus 1978) y L'Amérique au jour le jour de Beauvoir (1948). Este interés debe relacionarse no solo con las estrategias diplomáticas norteamericanas, sino también con la influencia que ejercen en estos escritores (especialmente Sartre y Beauvoir) las producciones culturales estadounidenses y, más concretamente, géneros populares como el western y el cine negro (que será reivindicado como base de la llamada novela objetiva). En España, el género se retoma en los años cuarenta con las crónicas de Juan Larch (Siluetas de América. Impresiones recientes de un periodista español, 1943), Gaspar Tato Cumming (Nueva York. Un español entre rascacielos, 1945), Diego Hidalgo (Nueva York. Impresiones de un español del siglo XIX que no sabe inglés, 1947), Luis Amargós (Estados Unidos. Viaje de un turista curioso, 1947) y Joaquín CalvoSotelo (Nueva Yorken retales, 1947) (Alarcón Sierra 2015:12). 
La popularización de la cultura americana no se evidenciará hasta la década siguiente, a partir de 1953 -momento en que se produce una progresiva americanización de determinados espacios sociales, culturales e institucionales españoles, en paralelo a la introducción gradual de la filosofía mercantil del libre comercio (Niño 2012)-. En este proceso es clave el papel que asumirán intelectuales y escritores como Julián Marías y Josep Pla, con libros de viajes que relatan sus respectivas estancias en Estados Unidos, basados en crónicas periodísticas de amplia difusión. Esto coincide con la vindicación que, desde las páginas de las publicaciones Revista y Laye, el crítico Josep M. Castellet hace de la novela norteamericana. Castellet se interesa por las novelas de Faulkner y Steinbeck, ya que, basándose en Qu'est-ce que c'est la littérature? (1948), de Sartre, las considera apropiadas para exigir la participación activa del lector en el proceso interpretativo (Dasca 2015).

Entre la literatura de viajes a los Estados Unidos publicada en España entre 1953 y 1960, encontramos estos seis títulos: De Nueva York a California (1953), de Antonio Heras; Norteamérica vista por un hombre de negocios (visión del viajero) (circa 1954), de Félix Estrada Saladich; Manhattan de refilón. Nueva York contada por un español (1955), de Manuel Tovar; Norteamérica a la vista (1956), una recolección de artículos escritos por el corresponsal de La Vanguardia en Nueva York, Ángel Zúñiga; el Dial poético da viaxe dun galego pol-os Estados Unidos (1958), antología de poesías en gallego de José Rubinos; y Los Estados Unidos vistos de cerca (1960), de Santiago Nadal. Su aparición puede interpretarse como respuesta a una demanda in crescendo, que hace que los periódicos envíen los primeros corresponsales transatlánticos regulares. Con el tiempo, esto conlleva el desarrollo de una literatura de viajes que, de alguna forma, da continuidad al imaginario ya existente, adaptándose a los clichés del contexto de postguerra. En la mayoría de estos libros lo que atrae es la posibilidad de ofrecer una experiencia 'directa' de la vida en el país, relatada por una amplia tipología de escritores, que incluye desde el hombre de negocios amateur en el oficio hasta el periodista cultural y/o político.

\section{El relato de viajes}

En términos generales, la literatura de viajes se caracteriza por ser una forma literaria de carácter híbrido, cuya temática es el periplo (real) realizado por un yo narrador, relatado a posteriori, y publicado una vez ha vuelto al lugar de origen. El relato, consecuentemente, se enuncia con posterioridad a la experiencia e implica una comunicación diferida con el lector (Spang 2008: 25). Sin relato, además, no hay literatura de viajes, ya que 'El relato de viajes es, pues, el relato de un viaje hecho discurso (cuyas marcas pueden ser más o menos explícitas), no el viaje en sí' (Rubio Martín 2008: 33).

Los dos libros que nos ocupan son el resultado, de hecho, de dos procesos de comunicación diferida: el primero concierne a la publicación de la crónica, de forma fragmentaria, en la prensa; y el segundo, la edición de estos materiales, ya conocidos por el público, en forma de libro. En el caso de Marías el viaje incluye tres experiencias: el curso académico 1951-1952, pasado en Massachusetts, el 
semestre de primavera de 1955, en Los Angeles, y un semestre de primavera de 1956, en New Haven. El viaje de Pla, en cambio, fue mucho más breve (sólo duró seis días de verano de 1954). Si bien Marías aprovechó su estancia académica para 'vivir' el país y explicarlo a sus lectores, Pla viajó por encargo del editor del semanario Destino, Josep Vergés.

Ateniéndonos a la definición del género hecha por Idoia Arbillaga, nos encontramos con textos ensayísticos que describen un viaje real 'presentado mediante el desarrollo de un itinerario topográfico' parcial (2005: 94). En el caso que nos ocupa tenemos un mismo espacio (Estados Unidos), visitado a lo largo de un periodo concreto y reportado como crónica periodística de base autobiográfica. Más específicamente, Marías escribe mientras trabaja, durante un año, en el Wellesley College y la Universidad de Harvard; durante un semestre, en la Universidad de Los Angeles, y, finalmente, otro semestre en la Universidad de Yale. Sus crónicas hablan de la vida universitaria y social en estas instituciones y, por extensión, de Nueva Inglaterra y California. El reportaje de Pla, en cambio, es urbano: se centra principalmente en la ciudad de Nueva York. Más allá de la experiencia del día a día, los dos libros incluyen referencias a las imágenes que la literatura de viajes y el cine han proporcionado del país, contra, o a pesar de, las cuales se impone la voz de los autores y sobre las cuales, como veremos, se erigen algunos de los estereotipos construidos.

En Marías el interés recae en las formas de vida de los norteamericanos, especialmente de los que no residen en las grandes urbes y que, por ese motivo, han estado poco presentes en el imaginario europeo. Pla, en cambio, se desplaza en coche para visitar los principales atractivos turísticos de Nueva York. Ambos explican, con entusiasmo, la impresión que les produce la sociedad norteamericana, sobre todo por su espíritu de libertad y de abundancia material, dos características inexistentes en la sociedad española de posguerra, víctima de una gran carestía de alimentos y de la férrea represión impuesta por la dictadura.

Una buena muestra de que ambos libros conectaron con el público a quién se dirigían son sus reediciones. El libro de Marías, publicado en 1956, tuvo una segunda edición un año después de su publicación, donde, además de las estancias de 1951-1952 y 1955, incluye artículos relativos a la de 1956; ${ }^{1}$ el de Pla, basado en notas de viaje, a partir de las cuales escribió los diez reportajes de Destino, se recogió en dos libros: el Viaje a América (1960) y el Week-end (d'estiu) a New York, una traducción al catalán de los artículos, con ampliaciones y modificaciones estilísticas importantes, publicada en 1955. Este texto será recogido en el volumen 34 de su Obra completa, bajo el título Les Amèriques (Pla 1978: 11-227), donde se incluyen, también, viajes posteriores al continente americano. ${ }^{2}$ Ambas obras obtuvieron el premio Pi i Sunyer del Instituto de Estudios Norteamericanos de Barcelona, creado en 1954 con el objetivo de reconocer obras de divulgación sobre los Estados Unidos. En su primera edición fue el libro de Marías el galardonado, mientras que la edición catalana del libro de Pla lo obtuvo en 1955.

1 En nuestro artículo nos basaremos en la edición de 1957.

2 En este trabajo partiremos de la edición de Viaje a América 1960. 
Como indica Arbillaga, en la evolución de la literatura de viajes es clave el papel de la tradición del género y los cambios introducidos en el tratamiento retórico y tópico. En este sentido, la estudiosa observa que el relato del viajero contemporáneo tiene poca objetividad (Arbillaga 2005: 38) porque aspira a transmitir una vivencia mediante elementos propios de la forma autobiográfica. El elemento subjetivo se evidencia, en ambos autores, en el uso de la primera persona del singular y en la construcción de una identidad literaria que corresponde, respectivamente, a la del 'profesor' universitario (Marías 1957: 9) y a la del 'turista sumiso y obediente' que cumple con los itinerarios previstos (Pla 1960: 96). Esta construcción de yoes es una marca propia del discurso memorialístico y, a la vez, una técnica procedente de la novela (Arbillaga 2005: 95).

El componente subjetivo permite, por un lado, evocar sensaciones y fomentar la contemplación (Spang 2008: 26-27) y, por el otro, incrementar la reflexión y exposición (Arbillaga 2005: 97). Así, por ejemplo, Marías, a partir de la observación, hipotetiza por qué los norteamericanos sonríen continuamente:

¿Sonríen los norteamericanos porque son felices? ¿O más bien para serlo? Por supuesto, para parecer que lo son, porque no es de buen gusto la melancolía, y la tristeza es bastante incorrecta. [...] Pero en su significación más honda y verdadera, la sonrisa es la expresión de la comunidad, el reconocimiento de que el prójimo existe y debe ser amado como uno mismo [...], la proclamación de la convivencia como bendición. (1957: 70-71)

Este fragmento nos muestra, además, el modus operandi del escritor, de base especulativa: a partir de una observación sobre la realidad, formula una pregunta, establece distintas hipótesis y acaba asumiendo la que, por el contexto cultural (o, más concretamente, su experiencia en un contexto cultural determi- nado, que le es nuevo), le parece más válida. Su hipótesis, sin embargo, es tan válida como cualquier otra, ya que se basa en una fundamentación totalmente subjetiva.

La prosa de Pla, en cambio, destaca por la inclusión de largos párrafos de evocación sensorial, canalizadores de emociones. Aquí tenemos una descripción del efecto, propio de la falacia patética, que le produce la contemplación del crepúsculo: 'Aparecieron las luces en los centenares de ventanas de la estructura elevadas, y el chorro luminotécnico comercial de las calles -rojo, verde, amarillo, blanco-. Se suspendió sobre la inmensa ciudad como un halo rojizo, de proporciones cósmicas, que me produjo una angustia extraña e inexplicable' (Pla 1960: 58). En esta cita vemos como la descripción, como dice Bou, responde a la 'capacitat de generar necessitat i sentit' a partir de la experiencia (1997: 17). Del conjunto de elementos que configuran la retórica planiana, aquí podemos destacar el uso de la iteración como recurso de cohesión textual (a través de la repetición de la imagen de las luces: chorro luminotécnico, halo rojizo), la enumeración (para expresar la profusión de colores: rojo, verde, amarillo, blanco) y la selección de adjetivos (con finalidad hiperbólica -'proporciones cósmicas'- o con la voluntad de concretar una emoción -'una angustia extraña e inexplicable'). ${ }^{3}$

3 El uso de la cursiva en este párrafo es de la autora. 
El espíritu divulgativo obliga al uso de un estilo 'medio, conversacional y coloquial' (Spang 2008: 23) que facilita la difusión del texto entre una audiencia amplia. En ambos textos encontramos unos marcadores de opinión personal. Es el caso de las conjunciones quizá, tal vez y acaso y de verbos como parecer o creer, que expresan duda o certitud. En Marías, una marca de coloquialidad son las múltiples preguntas que provocan determinadas afirmaciones, con las cuales describe (y connota) el paisaje donde vive. Veamos un ejemplo:

En las ciudades americanas, por debajo de sus estructuras, se suele adivinar el campamento; pero aquí tiene no sé qué aire de ficción e irrealidad. Quizá por eso tiene toda la ciudad un aire festival y como de vacaciones, que no se sabe explicar bien. ¿Tal vez el clima suave y perdurablemente veraniego? ¿Acaso la presencia cercana de tantas playas y de los montes y colinas que se descubren por encima de las casitas blancas, rosas, verdes? ¿La costumbre de vestirse tantas personas de un modo pintoresco, con lo que se llama casuals, a diferencia de la más entonada y urbana San Francisco o de las ciudades del este? (1957: 264)

Las crónicas de Pla, a su vez, interpelan al lector incluyendo incisos donde muestra sus dudas sobre lo que observa. Así lo ilustra esta afirmación del escritor en cuanto a la arquitectura del Rockefeller Center: 'El conjunto forma la más gigantesca fortaleza urbanística -que yo sepa- que el hombre ha levantado en el curso de la historia, la agrupación de masas plásticas más grandes del planeta' (1960: 84). En ella podemos observar el uso de un verbo dubitativo ('que yo sepa') en una descripción con un superlativo aplicada a un adjetivo amplificador ('la más gigantesca fortaleza'). ${ }^{4}$ El inciso matiza una afirmación que el lector podría considerar excesiva y, a la vez, incide en el impacto que provoca el edificio en el espectador.

Otro elemento propio del lenguaje coloquial es la dialogización, una técnica que, recuerda Spang, puede implicar una ampliación potencial de las perspectivas con que se muestra la realidad de la experiencia (2008: 24). Uno de los autores más conocidos por el uso de diálogos es Camilo José Cela, que hizo uso profuso de ellos en Viaje a la Alcarria (1948). En Pla volvemos a encontrar este recurso, muy habitual en su obra, empleado a fin de proporcionar una información recurrente. Este es el objetivo, verbigracia, del diálogo incluido en el capítulo 'Nueva York es la realización de una Europa frustrada', donde uno de sus anfitriones, míster Ellers, le hace una serie de preguntas que solo sirven para reiterar sus intuiciones sobre la ciudad, intuiciones que irán repitiéndose hasta convertirse en la tesis fundamental del libro (explícita en el título del capítulo) (Pla 1960: 79-81).

La descripción es otro de los elementos constitutivos de la literatura de viajes. Así, Carrizo apunta que 'los relatos de viaje constituyen un tipo de discurso narrativo- descriptivo en el cual la segunda función absorbe a la primera, aún en momentos en que se relatan aventuras, ya que éstas no empujan al receptor hacia la averiguación del desenlace, sino que lo retienen, como cualquiera de los seres u objetos descritos, en el sistema de cualificaciones que constituye la función privativa de la red textual' (Carrizo Rueda 1997: 13). En Marías, la descripción le sirve para dar entidad (o concreción visual) a esa idea, tan insistente en su discurso, de

4 El uso de la cursiva en este párrafo es de la autora. 
que la verdadera vida norteamericana se encuentra en los pueblos. Así lo expresa en este fragmento, casi costumbrista, donde describe su paseo bordeando el río Wilshire, en Los Angeles:

Nadie, nadie en las aceras; para mí los dos lados; sólo de tarde en tarde un señor con un paquete, que ha dejado en su coche, se dirige a su casa; o una dama sale de la suya y sube a su automóvil color cereza; y otra con blusa y pantalones, recoge del césped el periódico de la tarde, que han arrojado, y vuelve a entrar; a lo sumo, ya cerca de la zona comercial, una vieja señora anda pausadamente; pero tampoco pasea: lleva en la mano una carta con sobre de correo aéreo y se encamina al buzón de la esquina. (Marías 1957: 246-47)

En cambio, en Pla, la descripción sirve para elaborar un discurso basado en el humor - el humor con que se identifica su estilo y su mirada moral. Véase, como ejemplo, esta observación sobre el idioma: 'Los ingleses hablan como pájaros. Los americanos, no son, quizá, tan pajariles como los ingleses, porque han cargado mucho su idioma de nasalidad' (1960: 76). En la mayoría de los fragmentos que hemos analizado, la descripción procede a partir de la acumulación y la metáfora, y es debidamente adjetivada a fin de reproducir el efecto de 'ebullición mental' que, repetidamente, la ciudad ocasiona en el escritor. Así lo expresa en esta descripción del puerto:

El puerto de Nueva York no es solamente grandioso. Tiene asimismo una belleza viva y colorística. Su pátina portuaria es perfectamente comparable con la de los puertos más bellos del norte de Europa. Es un puerto del que está totalmente eliminada la frialdad del cemento armado como asimismo el colosalismo crispado. Un paseo por las magníficas avenidas que le siguen en toda su extensión, avenidas agitadas por un tránsito de mercancías fenomenal, ayuda a comprender muchísimo esta ciudad. (Pla 960: 73)

Según Arbillaga la 'dispositio [del libro de viajes] se constituye cardinalmente por razón del discurso descriptivo, seguido del narrativo, y su elocutio se manifiesta mediante la preferencia por la primera persona, por la virtud de la perspicuitas, por el estilo medio o bien epistolar, y por el uso característico, si no privativo, de ciertas figuras retóricas como el recurso a otras obras y otros procedimientos formales' (Arbillaga 2005: 94). A los elementos procedentes del registro coloquial y la importancia de la descripción en el relato de ambos escritores, podemos añadir, ahora, el uso del género epistolar con fines estructurales. Este es el caso del volumen de 1955 donde Pla recoge sus crónicas en catalán, Week-end (d'estiu) a New York. Este libro constituía el tercer volumen de la serie 'Cartes de lluny' (Cartas de lejos), articulada sin seguir las convenciones del género epistolar (los textos no tienen un destinatario ni una fecha de escritura), pero difundida bajo el epígrafe de cartas con un objetivo comunicativo específico: señalar la relación de proximidad con que se quiere establecer el vínculo con el lector.

¿Cuáles son, finalmente, los temas propios del género que observamos en los libros de Marías y Pla? En su conjunto, la literatura de viajes tiene una 'temática única' (el viaje en sí) e incluye 'libros ensayísticos, poéticos, narrativos o incluso dramáticos' (Arbillaga 2005: 59). En realidad, se trata de un género caracterizado 
por su fragmentariedad, cuyo objetivo es el mismo que el de los géneros didáctico- ensayísticos: docere, delectare y movere (Spang 2008: 26). A pesar de su heterogeneidad, el relato del viaje constituye una entidad autónoma, con un inicio y un final. Su autonomía está determinada, a la vez, por el hecho de que el periplo constituye una unidad de sentido en el decurso de una vida (Bou 1993: 159-60). Todo esto se ve en los relatos de Los Estados Unidos en escorzoy Viaje a América, precedidos por paratextos donde se explicita que el viaje es lo que justifica el relato y le da un sentido de unidad. La forma autobiográfica, como hemos visto, es lo que permite el desarrollo del viaje como tema.

\section{Una determinada imagen del país}

Una vez analizadas las características formales de Los Estados Unidos en escorzo y Viaje a América a fin de establecer sus elementos característicos en el marco de la poética del género, pasemos a analizar su imaginario desde la perspectiva imagológica. Nuestra aproximación partirá de la definición que da Pageaux a la disciplina. Concretamente, Pageaux la entiende como el ámbito que se dedica a explicar y comprender la imagen como lenguaje simbólico dentro de un sistema literario y un imaginario social (Pageaux 1994: 62).

Al crear imágenes representamos una realidad cultural mediante la cual se revela el espacio social, cultural, ideológico e imaginario de que formamos parte (1994: 60). En este sentido, analizar la imagen de Estados Unidos en los libros de Pla y Marías implica estudiar las condiciones de la representación: saber quiénes representan y quién está representado, a quién se dirige la representación, y, en último término, qué instancia produce y legitima la representación. Hacerlo nos obliga, a la vez, a tener en cuenta el componente subjetivo de las imágenes, puesto que éstas participan en la construcción de un mundo 'as an object of knowledge and as a source of meaning' (Ridney 2007: 415).

El relato se elabora según unas premisas que, de forma manifiesta, guían las aproximaciones de ambos viajeros a la realidad. En el caso de Marías, este escribe impelido por la necesidad de ir más allá de los límites impuestos por los numerosos visitantes europeos, que han reproducido los mismos 'supuestos' de lo que han visto. Así, afirma, 'El único medio de llegar a entender algo de la vida norteamericana es... vivirla. Hacer la experiencia de sumergirse en lo cotidiano, de repetir muchas veces las mismas sencillas acciones, de hacerse familiar un trozo del país' (Marías 1957: 65). Para hacerlo, defiende la necesidad de un conocimiento directo, de base empírica, muy parecido al concepto de experiencia según lo entiende Whilhelm Dilthey en De Leibniz a Goethe (1945). Según Dilthey (1945: 338), filósofo que Marías conocía bien, la experiencia contiene en sí un aspecto por el cual es posible que las impresiones se unan a los elementos en la conciencia; es por este motivo que la experiencia es viva, en la medida que, como base del conocimiento, pone en relación los estados anímicos del individuo con su conocimiento racional. Por su parte, la experiencia relatada por Pla obedece a la consigna de que lo que puede ver en América es una nueva versión, mejorada y ampliada, de lo que conoce de la vieja Europa: 'Nueva York produce una ebullición mental tremenda -a las personas medianamente sensibles- preci- 
samente porque plantea a cada momento los problemas elementales de nuestro continente, que no solamente no están resueltos, sino que han emprendido un camino en que jamás serán resueltos' (Pla 1960: 104).

A pesar de sus reservas, lo que cuentan ambos escritores estará determinado por unos apriorismos, que se traducirán, en Marías, en un interés especial por las formas de relación social y, en Pla, en la impresión de satisfacción material que le produce la abundancia norteamericana. En su elaboración, los relatos se fundamentan en una poética (de base especulativa, en Marías; materialista, en Pla) que no solo vehicula unos determinados valores morales, sino que también se erige como dispositivo autentificador de sus escritos, en la medida que 'Any valid judge- ment on the authenticy of travel writing [...] necessitates attention to its poetic form' (Meier 2007: 446).

En los dos libros, el relato es vehiculado por la voz de un narrador que integra la voz del otro, teniendo en cuenta, explican los dos autores, distintas representaciones anteriores, difundidas por el cine y la literatura. Utilizando recursos como la recurrencia, la variación y la analogía, los escritores consiguen imponer al lector su poder absoluto sobre la interpretación de lo visto (Champeau 2008: 102), en unos textos donde raramente aparecen personajes con voz propia. Como hemos visto, este control sobre la realidad construida se elabora, en Marías, a través de la asunción de una hipótesis y su validación como verdadera y, en Pla, con la introducción de unos diálogos cotidianos donde la intervención del interlocutor obedece a la finalidad de validar lo que dice el narrador.

Con la interpretación de una serie de elementos predeterminados temática- mente (el itinerario, el transporte, el alojamiento y la duración del viaje) Marías y Pla crean una imagen única de Estados Unidos, de la cual forman parte, autentificada por su poética. Con su relato consiguen no solo elaborar una representación de sí mismos (ambos, por ejemplo, se presentan como viajeros solitarios, aunque viajan acompañados) sino también una imagen de lo que ven y viven. Lo visto, una vez relatado, constituye su ethos. En la construcción de su representa-ción mental del país se basan en un repertorio fundamental de palabras (muchas de ellas sintetizadas en los títulos de los capítulos), ${ }^{5}$ que implica una relación jerarquizada respecto al marco espaciotemporal (la selección del itinerario según unos objetivos concretos), la oposición entre yo y el otro (entre el escritor y los norteamericanos, o éstos y los españoles/ catalanes) y una concepción del texto

5 En los títulos de los capítulos de Marías podemos destacar, entre otros, conceptos como europeo, hispanismo, vida intelectual frente a casas de cristal, soledad, las compras, el drugstore, la televisión, lo público, el hombre medio, el pueblo civil, los negros y la mitad femenina. Como vemos, las identidades de origen (ya consabidas) se oponen a conceptos de índole social, que identifican grupos, formas de relación o de consumo. Los nueve títulos de los artículos de Pla, que constituyen sintagmas mucho más largos, se basan en la descripción de sus impresiones de la ciudad: 'Una ciudad de prodigiosa abundancia', 'Todo va por sus pasos contados', 'Hay que ir a América con la fuerza de la juventud', 'La maravilla del Museo Metropolitano y el Barrio de Harlem', 'Vivir a veinte millas de la ciudad y tener una casita', 'La clave del pasado, del presente y del porvenir de Europa', 'Proyectar el bienestar sobre el mayor número de personas', 'El teléfono y el “frigidaire”, dos elementos esenciales' y 'Llegó la hora de partir'. 
literario como expresión antropológica. Todas estas opciones responden a una determinada coherencia: la de la psicología del locutor (Beller 2007: 12). Como hemos visto, este locutor-autor establece una autoridad mediante la cual 'is able to convey, construct, modify or negate concepts of the alien' (Meier 2007: 449).

Cabe decir que tanto Marías como Pla parten de una actitud de admiración, ya que ven la cultura norteamericana como positiva y complementaria a la suya (Pageaux 1994:72). En este sentido, su obra muestra una realidad que contrasta con la española, lugar en el que residen sus lectores, realidad que había sido objeto de crítica en la literatura de viajes publicada desde la generación del 98. En el contexto de postguerra, según recuerda Arbillaga, son los novelistas sociales los que, con clara voluntad de denuncia, iniciarán peregrinaciones por España (este es el caso del Viaje a la Alcarria, 1948, de Camilo José Cela, los Campos de Níar, 1960, de Juan Goytisolo y Caminando por las Hurdes, 1960, de Antonio Ferres y Armando López Salinas, entre otros) (Arbillaga 2005: 38-39). El componente de denuncia de estos libros no es el mismo, pero; así, según una parte de la crítica, el libro de Cela está exento del compromiso sociopolítico que asumen Goytisolo, y López Salinas y Ferres, y su denuncia se limita a mostrar, como hizo anteriormente la generación del 98, 'las miserias, atrasos y estado de abandono de una sociedad adormecida' (Pozuelo Yvancos 1990: 49). La emergencia del género durante la postguerra puede relacionarse, también, con la necesidad de conectar con el público e instruirlo después de los años de parálisis cultural posteriores al fin de la guerra civil.

Pese al entusiasmo con que abrazan la experiencia, la literatura de Marías y Pla contribuye a la difusión de estereotipos, que se manifiestan tanto en la descripción de lo que les pasa o ven como en la narración de historias. Todos ellos participan, claramente, en la creación de unas determinadas formas de alteridad. Para analizarlo nos centraremos en varios ejemplos que nos interesan en la medida que constituyen el centro de su argumentario sobre el periplo. En última instancia, su imaginario nos interesa porque pone al descubierto un sistema de valores (individuales y colectivos) basado en diversos 'white, male, middleclass, heterosexual myths and prejudices' (Holland y Huggan 1998: viii).

Marías escribe un libro de viajes que, como el de Pla, se divide en capítulos temáticos (cuyos motivos se expresan en los títulos), a través de los cuales se puede seguir un itinerario de recorrido y duración mucho más amplios que el de Pla. Su propósito es explicar lo que vive a partir de su convivencia con los norteamericanos. Este es el punto de partida de un proceso de conocimiento lento y dilatado en el tiempo que infunde el tono de lo que escribe. Contra el 'turista' atento a los 'detalles pintorescos' (Marías 1957: 158) el escritor quiere explicar la forma 'real' de vivir (1957: 161), sin reconocer que su creación recurre a un imaginario estructural, fruto de 'the tourist industry' que pretende menospreciar (Holland y Huggan 1998: xi). El relato de su experiencia implica una expresión simplificada de la realidad que permite establecer una relación social de conformidad (Pageaux 1994: 63) con su momento histórico.

En el marco de postguerra esta conformidad encaja perfectamente con la voluntad de dar a conocer el país entre los lectores españoles en el periodo poste- 
rior a los acuerdos de 1953. También se adecúa al programa desarrollado por la Congreso para la Libertad Cultural, dependiente de la Agencia Central de Inteligencia de los Estados Unidos, una asociación anticomunista fundada en 1950, con la voluntad de 'ser un emisario de los logros de la cultura norteamericana' en Europa (Stonor Saunders 2001: 123-24, 129-31, 145-46) con la cual colaboró Marías a partir de 1959 (Amat 2009). La participación de intelectuales como Marías en el Comité Español del Congreso debe entenderse, por un lado, como parte de su implicación en las redes de oposición a la dictadura, muy diversas ideológicamente, y, por el otro, como muestra de su compromiso en defensa de la civilización occidental y la cultura liberal (Glondys 2015). Su experiencia académica en Estados Unidos, previa a su vínculo con el Comité, pone de manifiesto, asimismo, la creación de un clima favorable al entendimiento cultural entre ambos gobiernos (Delgado Gómez-Escalonilla 2005).

En su caso, Marías contrapone lo que vive con el carácter de la vida en España, incurriendo en tópicos como el de la impuntualidad o la importancia de los cafés. Su visión parte de una idealización, según la cual la sociedad -o el estado social (1957:318)- se convierte en un freno contra la soledad (1957: 319). A estas consideraciones generales, se le añade el interés que le despiertan las formas de relación social de un territorio 'inacabado' (59) que no ha abierto espacios, a su entender, para la vida intelectual. Su visión peca de ingenuidad al referirse a la imagen 'conmovedora' que ofrecen los afroamericanos o a la actividad y el dinamismo de unas mujeres que 'circulan, elásticas y seguras' (189), adjetivos que, como el diminutivo negritos, connotan valores asociados, respectivamente, a la circulación (un tópico asociado al librecambismo promovido por el cine de la época) y a la compasión (en la simplificación de un tema altamente controvertido en su momento como el conflicto racial). También puede sorprendernos que considere (¡en plena guerra fría!) que el gasto militar no afecta al bienestar individual (210) y que el comunismo no es visto como una amenaza (212). En conjunto, este imaginario es coherente con la pragmática que guía su escritura: descubrir, con la propia vivencia, el lado amable, y familiar, del estado más poderoso del mundo empleando un vocabulario operativo dentro de un 'readily identificable semantic field' (Holland y Huggan 1998: 5).

El uso de este vocabulario, a su vez, corrobora la visión deliberadamente etnocéntrica del viajero, basada en la redundancia, la discontinuidad y la irrealidad (Pratt 1992: 2) en el uso de determinadas ideas; una aproximación que excluye cualquier posibilidad de transformación del sujeto y que pone en evidencia unos prejuicios de género, clase y cultura. Tanto Pla como Marías se limitan a reproducir estereotipos establecidos por la literatura europea anterior, que asociaba los afroamericanos a la indolencia y el candor y la American girl a la independencia (Alarcón Sierra 2010: 150,136). Ambos colectivos son representados a través de la adjetivación del cuerpo (el color de la piel y los dientes en el caso de los afroamericanos; la proporción y la seguridad en el caso de las mujeres) y son objeto de comparaciones que los deshumanizan. Así, en Pla, mientras los negritos son 'una especie de gitanería de la negrura y del pelo rizado de la selva' (1960: 95) las 
americanas son 'un tipo de animal femenino prodigiosamente bello, de pierna y muslo largos, de cuerpo admirablemente proporcionado, de facciones marmóreas y estatutarias' (1960: 56).

El reportaje de Pla combina el relato propio de la crónica de viajes con notas de interpretación sociológica y antropológica sobre la vida de los norteamericanos. En el primer caso, las descripciones alternan documentación material y documental con impresiones estéticas expresadas de forma analógica. En el segundo, Pla opina sobre una serie de tópicos (sobre la comida, los transportes o, como hemos visto, las mujeres), a menudo introducidos a través de relatos breves o anécdotas, que sintetizan su experiencia a partir de la realidad. Todo con el objetivo de constatar, reiteradamente, que Nueva York no es más que una Europa más rica y con más abundancia. La imagen que construye de la ciudad implica, como todas las imágenes en general, una jerarquía, y pone en evidencia una cultura tautológica.

Así, en el capítulo 'Restaurante típicamente americano' Pla corrobora, con su experiencia y su opinión, la imagen preconcebida que el lector puede tener de este tipo de servicio, expresada con la palabra (explotada en el sentido turístico $\mathrm{y}$, también, social) del típicamente. Pla va a comer a un restaurante automático y queda admirado de la facilidad con que se desarrolla el 'ritmo alimenticio' en un espacio abarrotado de gente. Después de detallar qué come y bebe la gente, y con qué cantidad, deduce que: 1. en 'Nueva York la presión ajena regula en gran parte la propia vida y la moldea fatalmente' (1960: 77); y 2. 'Los americanos han llegado a la conclusión de que, si la cocina profesional no es muy buena, es preferible comer los platos envasados' (1960: 78). Ambas afirmaciones no hacen sino confirmar su tesis inicial: el orden de una sociedad que, aunque crece muy rápidamente y con gran copiosidad, sabe autorregularse sin menester reglas explícitas. Esta imagen (asociada a la capacidad de emprendimiento y organización burguesa) implica, a su entender, un estado de espíritu que Europa ya no tiene y que es favorecido por una libre concurrencia que convierte a los norteamericanos en un 'pueblo tocado por el signo de lo mayúsculo' (Marías 1957:132).

\section{Conclusión}

Amenos y didácticos, los libros de viajes a América de Marías y Pla se inscriben en una realidad en progresiva transformación, marcada por el fin de la autarquía y el inicio de la liberalización económica. En este contexto, Marías difunde una imagen positiva del espacio académico norteamericano, resultado de su admiración por los valores de la Europa liberal. Pla, en cambio, europeíza su representación de Nueva York, vinculándola a las ciudades que conoció antes de la guerra. La construcción (elocutiva y dispositiva) de ambos libros se sustenta a partir de las convenciones genéricas, cuyo reconocimiento por parte del lector ayuda a su difusión. Se trata de obras con un elevado componente subjetivo, basadas en una visión etnocéntrica de la realidad, que reproduce estereotipos difundidos por la tradición europea de literatura de viajes a Estados Unidos. El resultado es 
la creación de una imagen idealizada del país, fácilmente asumible en la etapa posterior a los acuerdos de 1953, que, en plena guerra fría, supone una neutralización de cualquier tipo de controversia (como el problema racial o la amenaza comunista). Este imaginario será objeto de revisión por parte de la literatura posterior, especialmente a partir de los sesenta y setenta, décadas marcadas por el desarrollo de una industria turística que, en el contexto internacional, supone una identificación del exotismo del viaje con la plenitud (Pratt 1992: 221) y, en el español, es el resultado del Plan de Estabilización de 1959. Esta etapa, sin embargo, queda al margen de nuestro estudio.

\section{Obras citadas}

Alarcón Sierra, Rafael, 2005. 'Los libros de viaje en la primera mitad del siglo XX: Julio Camba: "La rana viajera"', en Los libros de viaje: realidad vivida y género literario, coord. Patricia Almarcegui Eduayen y Leonardo Romero Tobar (Madrid: Universidad Internacional de Andalucía y Akal),pp.158-95.

-, 2010. Una rana viajera: las crónicas y libros de viaje de Julio Camba (Sevilla: Renacimiento).

—, 2015. 'Llámalo sueño: Nueva York en la narrativa española', Ínsula, 821: 11-16.

Amargós, Luis, 1947. Estados Unidos, viaje de un turista curioso (Madrid: Hesperia).

Amat, Jordi, 2009. 'Europeísmo, Congreso por la Libertad de la Cultura y Oposición Antifran- quista (1953-1966)', Historiay Política, 21 (enero-junio): 55-72.

Arbillaga, Idoia, 2005. Estética y Teoría del Libro de Viaje. El 'viaje a Italia' en España (Málaga: Universidad de Málaga).

Beauvoir, Simone de, 1948. L'Amérique au jour le jour (París: Éditions Paul Morihien).

Beller, Manfred, 2007. 'Perception, imatge, imagology', en Imagology: the Cultural Construction and Literary Representation of National Characters: A Critical Survey, ed. Joep Leerssen y Manfred Beller (Amsterdam y Nueva York: Rodopi), pp. 3-16.

Bou, Enric, 1993. Papers privats: Assaig sobre les formes literàries autobiogràfiques (Barcelona: Edicions $62)$.

-, 1997. 'L'art del viatger: el cas de Josep Pla', L'Aiguadolç, 23 (primavera): 13-22. Disponible en: $<$ http://www.raco.cat/index.php/Aiguadolc/article/view/65238> [consultado el 12 de julio de 2019].

Calvo-Sotelo, Joaquín, 1947. Nueva York en retales (Madrid: Dossat).

Camba, Julio, 1959 [1917]. Un año en el otro mundo (Madrid: Espasa Calpe).

-, 2015 [1932]. La ciudad automática. Los Viajeros, 25. (Valencina de la Concepción: Renacimiento).

Cela, Camilo José, 1948. Viaje a la Alcarria: las botas de siete leguas, fotos de Karl Wlasak (Madrid: Revista de Occidente).

Cela, Camilo José, 1948. Viaje a la Alcarria (Madrid: Viaje a la Alcarria). Camus,

Albert, 1978. Journaux de voyage (París: Gallimard).

Carrizo Rueda, Sofía M., 1997. Poética del relato de viajes (Kassel: Reichenberger).

Champeau, Geneviève, 2008. 'Tiempo y organización del relato en algunos relatos de viajes españoles contemporáneos', en Elviajeen la literatura hispánica:de Juan Valeraa Sergio Pitol, ed. Julio Peñate Rivero y Francisco Uzcanga Meinecke (Madrid: Editorial Verbum), pp. 89-103.

Dasca, Maria, 2015. 'Josep Maria Castellet, un passeur cultural excepcional entre Nord-Amèrica i Catalunya', en Josep M. Castellet, editor i mediador cultural, ed. Enric Gallén y José Francisco Ruiz Casanova (Lérida y Barcelona: Punctum y Edicions 62), pp. 139-57.

Delgado Gómez-Escalonilla, Lorenzo, 2005. 'Cooperación cultural y científica en clave política. Crear un clima favorable a las bases USA en España', en España y Estados Unidos en el siglo XX, ed. Lorenzo Delgado Gómez-Escalonilla y María Dolores Elizalde Pérez-Grueso (Madrid: Consejo Superior de Investigaciones Científicas), pp. 207-243.

Dilthey, Wilhelm, 1945 [1914]. De Leibniz a Goethe, traducción de José Gaos, Wenceslao Roces, Juan Roura y Eugenio Ímaz, prólogo de Eugenio Ímaz (México: Fondo de Cultura Económica).

Dilthey, Wilhelm, 1957. Das Erlebnis und die Dichtung: Lessing, Goethe, Novalis, Hölderlin (Göttingen, Alemania: Vandenhoeck \& Ruprecht).

Estrada Saladich, F[élix], 1954. Norteamérica vista por un hombre de negocios. F. Biblioteca de iniciativas Comerciales, 4. (Barcelona: Editorial Quiris). 
Ferres, Antonio y Armando Salinas, 1960. Caminando por las Hurdes, ilustración fotográfica de Luis Buñuel y Oriol Maspons (Barcelona: Seix Barral).

García Lorca, Federico, 1987. Poeta en Nueva York, ed. María Clementa Millán (Madrid: Cátedra).

García-Montón, Isabel, 2002. Viaje a la modernidad: lavisión de los Estados Unidos en la España finisecular (Madrid: Editorial Verbum).

Glondys, Olga, 2015. 'El Congreso por la Libertad de la Cultura y su apoyo a la disidencia cultural durante el franquismo', Revista Complutense de Historia de América, 41: 121-46.

Goytisolo, Juan, 1960. Campos de Níjar, ilustraciones fotográficas de Vicente Aranda (Barcelona: Seix Barral).

Heras, Antonio, 1953. De Nueva York a California (Madrid: Espasa-Calpe).

Hidalgo, Diego, 1947. Nueva York. Impresiones de un español del siglo XIX que no sabe inglés (Madrid: Aguilar).

Holland, Patrick, y Graham Huggan, 1998. Tourists with Typewriters: Critical Reflections on Contemporary Travel Writing (Ann Arbor: University of Michigan Press).

Huvos, Kornel, 1972. Cinq mirages américains; les États Unis dans d'œuvre de Georges Duhamel, Jules Romains, André Maurois, Jacques Maritain et Simone de Beauvoir. Études de littérature étrangère et comparée, 68. (París: Didier).

Jardiel Poncela, Enrique, 1955. Exceso de equipaje. Mis Viajes a Estados Unidos-Monólogos-PelículasCuentos y Cinco Kilos de Cosas Más (Madrid: Biblioteca Nueva).

Jiménez, Juan Ramón, 1999. Diario de un poeta reciéncasado (1916), ed. Michael P. Predmore. Letras Hispánicas. (Madrid: Cátedra)

Larch, Juan, 1943. Siluetas de América. Impresiones recientes de un periodista español (Madrid: Diana Artes Gráficas).

Le Corbusier, 1965 [1937]. Quand les cathédrales étaient blanches. Voyage au pays des timides (París: Éditions Gonthier).

Leerssen, Joep, y Manfred Beller, 2007.Imagology: The Cultural Constructionand Literary Representation of National Characters. A Critical Survey (Amsterdam y Nueva York: Rodopi).

Marías, Julián, 1957 [1956]. Los Estados Unidos en escorzo (Buenos Aires: Emecé Editores).

Maurois, André, 1933. En Amérique (París: Flammarion).

- , 1939. États-Unis 39: journal d'un voyage en Amérique (Les Éditions de France).

- , 1945. Historia de los Estados Unidos, trad. del francés por F. Oliver Brachfeld. Colección Norteamérica, 2-3. (Barcelona: Editorial Lara).

- , 1946. Journal États-Unis, 1946 (Éditions du Bateau).

Meier, Albert, 2007. 'Travel writing', en Imagology: The Cultural Construction and Literary Representation of National Characters. A Critical Survey, ed. Joep Leerssen y Manfred Beller (Amsterdam y Nueva York: Rodopi), pp. 446-51.

Miranda-Barreiro, David, 2014. Spanish New York Narratives 1898-1936. Modernization. Otherness and Nation (Londres: Legenda).

Morand, Paul, 1930. New York (París: Flammarion).

Nadal, Joaquín, 1960. Los Estados Unidos vistos de cerca. Prólogo de Manuel Jiménez de Parga. Colección Áncora y Delfín, 190. (Barcelona: Destino).

Niño, Antonio, 2012. La Americanización de España (Madrid: Los Libros de la Catarata).

Pageaux, Daniel-Henri, 1994. La Littérature générale et comparée (París: Armand Colin).

Pinçonnat, Chrystel, 2001. New York, mythe littéraire français (Ginebra: Droz).

Pla, Josep, 1955. Week-end (d'estiu) a New York (Barcelona: Selecta).

- 1960. Viaje a América. Colección Áncora y Delfín, 173. (Barcelona: Destino).

-, 1966. Les Amèriques, en Obra completa, de Josep Pla. Vol. XXXIV (Barcelona: Destino), pp. 11227.

Pratt, Mary Louise, 1992. Imperial Eyes. Travel Writing and Transculturation (Londres y Nueva York: Routledge).

Pozuelo Yvancos, José María, 1990. 'Introducción', en Viaje a la Alcarria, por Camilo José Cela (Madrid: Espasa Calpe), pp.9-56. 
Ridney, Ann, 2007. 'Representation', en Imagology: the Cultural Construction and Literary Representation of National Characters: A Critical Survey, ed. Joep Leerssen y Manfred Beller (Amsterdam y Nueva York: Rodopi), pp. 415-18.

Rubinos, José, 1958. Dial poético da viaxe dun galego pol-os Estados Unidos. Texto gallego y versiones castellana e inglesa. Primer premio de poesia en el concurso de la 'Unity Galega' de Nueva York. (Habana).

Rubio Martín, María, 2008. 'Articulación del componente ficcional en el libro de viajes contemporáneo', en Elviajeen la literaturahispánica: de Juan Valeraa Sergio Pitol, ed.Julio Peñate Rivero y Francisco Uzcanga Meinecke (Madrid: Editorial Verbum),pp.31-45.

Spang, Kurt, 2008. 'El relato del viaje como género', en El viaje en la literatura hispánica: de Juan Valera a Sergio Pitol, ed. Julio Peñate Rivero y Francisco Uzcanga Meinecke (Madrid: Editorial Verbum), pp. 15-29.

Stonor Saunders, Frances, 2001 [1999]. La CIA y la Guerra fría cultural, trad. Rafael Fontes (Barcelona: Debate).

Tato Cumming, Gaspar, 1945. Nueva York. Un español entre rascacielos (Madrid: Febo).

Tovar, Manuel, 1955. Manhattan de refilón. Nueva York contada por un español (Barcelona: Editorial Iberia).

Zúñiga, Ángel, 1956. Norteamérica a la vista (Barcelona: Barna). 